\title{
1. Towards a more comprehensive understanding of boundary spanners in the context of public management and governance
}

\subsection{WHY STUDY BOUNDARY SPANNERS?}

In the field of public management and governance we see an increasing interest in boundary spanning behaviour, strategies and challenges. This is not surprising given the increasingly emphasized paradigm of crossboundary collaboration (for example Ansell and Gash, 2008; Kelman, 2007; O'Flynn, 2009; Osborne, 2006). Interdependencies among various state and non-state actors, the complex nature of public issues, and issues of fragmentation and coordination are amongst the key drivers for a rising attention for boundary spanners and their work (these drivers will be discussed more in detail in Chapter 2). The challenge of coordination and collaboration across boundaries has probably always been part of public sector organizations; however, due to a changing role of government and a changing context of governing, this challenge has become far more prominent (Edelenbos and Van Meerkerk, 2016; Klijn and Koppenjan, 2016; Torfing et al, 2012; O'Flynn et al, 2014). Boundary spanning is approached as a coping mechanism to meet these drivers and to infuse and consolidate collaboration among organizations (Van Meerkerk and Edelenbos, 2014; Williams, 2012).

Furthermore, we are witnessing a tremendous rise in initiatives of co-production and delivery of public services, in which public servants are increasingly expected to work with citizens in ways that cut across vertical service demarcations and organizational boundaries (Voorberg et al, 2015). In various fields of public policy-making and service delivery, coordination and collaboration across traditional organizational, sectoral and/or policy boundaries is stressed in order to design and deliver more effective and integrative public services (O'Flynn et al, 2014; Quick and Feldman, 2014; Williams, 2012). For example, in the field of health care, delivering support for families in deprivation or addressing the health, 
care and housing needs of people with conditions such as diabetes or dementia requires cross-boundary interaction of various government agencies (for example Needham et al, 2017). Moreover, increasing demands for user-oriented models of service delivery requires new ways of working between various agencies and with citizens to address outcomes that cut across conventional service demarcations. Comparable demands are seen in various other fields of public service delivery. For instance, in the field of urban regeneration there is an increasing attention to community-led planning and service delivery, which cuts across the boundaries of economic, physical and social sectors (Van Meerkerk et al, 2013). An example from another field concerns the rise in integrated water management approaches in which aspects of water (flood defences, water quality, etc.) are combined with spatial planning, ecology, environment, and economic development (Edelenbos and Teisman, 2013).

Also in the private sector, boundary spanning behaviour receives considerable and still increasing attention. Nowadays, private organizations operate in highly dynamic and volatile environments to which these organizations need to be attuned in order to stay competitive and achieve client satisfaction. Boundary spanning behaviour plays an important role in collecting and disseminating relevant information, enhancing knowledge exchange and learning, and adapting the organization to its environment (for example Tushman and Scanlan, 1981; Rosenkop and Nerkar, 2001). Furthermore, within an increasingly competitive, international, and dynamic environment, the importance of forming inter-organizational exchange relationships and collaborations has also grown. The growth of inter-organizational relationships puts organizations in a position where they need to partner in order to keep a competitive advantage in the environment. This has led to increasing attention on boundary spanning behaviour in building strategic alliances, managing partnerships, and relational governance (for example Ferguson et al, 2005).

Although we need to be aware of the specific context in studying boundary spanners, we can learn a great deal from private sector research on boundary spanning, in particular with regard to organizational and personal factors impacting on boundary spanning behaviour. Therefore we will also build on the knowledge from other scientific disciplines, such as business administration, organizational studies, social psychology, and management studies (see below). In this book, we conduct an interdisciplinary assessment of boundary spanning in order to get a more comprehensive understanding of the phenomenon.

This book pays explicit attention to boundary spanners. Boundary spanners undertake the cross-boundary work that is needed to develop coordination and collaboration across boundaries. Their role is therefore 
of significant importance in relation to cross-boundary endeavours. Boundary spanning is considered to be a core activity of contemporary public management (for example McGuire, 2006; O'Flynn et al, 2014; Torfing et al, 2012; Quick and Feldman, 2014). Moreover, as the push for more cross-boundary collaboration and cooperation in public governance has become stronger than ever before - exemplified by the tremendous rise in inter- and multiorganizational arrangements - the role and work of boundary spanners grows in significance. However, in the field of public management and governance, explicit attention and comprehensive focus on boundary spanners is remarkably enough underdeveloped (Williams, 2012; O'Leary et al, 2012). As Frederickson put it in his Donald C. Stone Lecture at the Annual Conference of the American Society for Public Administration over a decade ago (2007: 16):

It [is] always in the form of managers and officials. Effective collaboration is deeply dependent upon the skills of officials and managers. Organizations may appear to collaborate, but in fact it is individuals representing organizations who collaborate.

Although the attention to the role and importance of individuals is growing, this is still underemphasized as there seems relatively more attention to the dimensions of process and institution in the context of cross-boundary work and collaboration (for example Williams, 2012; O'Leary et al, 2012). According to O'Leary et al (2012: S70), "most of the literature on collaboration in the public sector focuses on organizations, with the role of the individual in collaborations receiving limited attention". While there are several books in different research areas on boundary-crossing strategies and practices (in both public and private sector contexts, see next section), there is little coherent and systematic attention to the role, behaviour, antecedents, and impact of boundary spanners. This book aims to start filling this lacuna.

\subsection{DEFINING BOUNDARY SPANNERS}

In this book, we define boundary spanners as

people who proactively scan the organizational environment, employ activities to cross organizational or institutional boundaries, generate and mediate the information flow and coordinate between their "home" organization or organizational unit and its environment, and connect processes and actors across these boundaries. 
Although this is still a quite broad definition of boundary spanners in order to capture various roles and components of boundary spanning work, it stresses in particular four aspects (which will be further discussed and elaborated in Chapter 3).

First, connecting actors across boundaries includes developing and maintaining actor relationships. This aspect thus emphasizes relational aspects of boundary spanning work, as particularly stressed in public management and governance approaches on boundary spanning (Van Meerkerk and Edelenbos, 2014; Williams, 2012). Boundary spanners have a wide array of contacts: successful boundary spanners are strongly linked internally and externally (Tushman and Scanlan, 1981). Second, an important part of the work of boundary spanners is to align and coordinate activities and processes across boundaries: within the home organization and the organizational environment (for example the network, partnership, customers, and clients). Internal and external linkages have to be maintained and coordinated. This includes the careful balancing of communication and coordination with internal linkages within the home organization and external linkages with stakeholders in the network and environment (Johnson and Chang, 2000; Van Meerkerk and Edelenbos, 2014). Third, the mediation of the information flow is explicitly mentioned. This component strongly builds on the organizational literature, mostly developed in a private sector context. It refers to the specific role of boundary spanners in information and knowledge exchange. This not only includes the collection and dissemination of information across boundaries, but often also involves translating and transforming information in order to make effective cross-boundary linkages (Tushman and Scanlan, 1981; Birkinshaw et al, 2017). The latter types thereby include sense-making and framing activities (Carlile, 2002; Williams, 2012). Fourth, management of interfaces and mediation of information also has an entrepreneurial quality, in that it involves individuals undertaking (proactive) action in response to mediation opportunities between actors, (policy) processes and issues (agendas) inside and outside organizational or institutional boundaries (Birkinshaw et al, 2017; Van Meerkerk et al, 2017; Williams, 2012). To get an image of how these aspects come together, Box 1.1 provides a reflection from a community leader on his role as boundary spanner in the context of an interactive governance process. 


\section{BOX 1.1 REFLECTION FROM A COMMUNITY LEADER ON HIS BOUNDARY SPANNING ROLE}

The following quote comes from a community leader involved in an interactive governance process which is triggered by a community initiative (for further details of this case study, see Van Meerkerk and Edelenbos, 2016). It illustrates the meaning and role of boundary spanners in such collaborative governance processes. The respondent describes his boundary spanning role and important skills for this as follows:

Eventually collaborative governance turns out to [be] creating relationships with people. It starts with acknowledg[ing] the importance of somebody's work, provid[ing] a compliment or a reflection. You need to get personally and professionally connected to someone. It is about creating a context, an atmosphere, in which get to know each other, you work together and become meaningful to each other. You need to get familiar with someone['s] interests, stories and language. It is important to show empathy for the interest, concerns and wishes others have. To me this is a conditio sine qua [non] in order to create connections in this complex world. [...] Language proficiency is an important skill you must have. This is about understanding and [being] able to use different kind[s] of languages, the language of bureaucrats, politicians, lay people and professionals. Often times as a networker and [boundary spanner] you are a translator amongst different people with different backgrounds and languages. Each language represents different norms, rules and values. [...] Another important aspect is to have an inspiring vision and put [...] a dot on the horizon, to where we can go to. This is not a concrete and very detailed vision, but an idea that is able to bind and connect people. A process of envisioning starts in which people together further fill in the vision and add all kind[s] of shapes and colors. It is more a bricolaged vision that is the product of a shared process. However, it is important that you fuel this process by coming up with a general vision yourself. It gives a sense of direction, a clue in a very fragmented and complex world in which everybody knows some pieces of [the] puzzle but don't always have the overview of what the puzzle exactly can look like. I am not the person who knows it all, and knows exactly where we all have to go to. This is a process of many people and mindsets; however, it is important that some direction is provided by a dot or different possible dots on the horizon.

Source: Authors' own empirical fieldwork conducted in 2014

We explicitly identify boundary spanners by their behaviour and activities and not by their formal organizational function. Boundary spanning behaviour includes different types of activities, such as collecting and transferring information, translating and transforming knowledge, facilitating interaction, negotiation and brokering activities, building relationships, and coordinating activities across boundaries. We will delve deeper into various boundary spanning activities and roles in this book, in particular in Chapter 3 (from a theoretical point of view), Chapter 4 (from a methodological point of view), and Chapter 5 (from an empirical point of view, describing different boundary spanning profiles). 
Although it can be argued that all street-level work in public services includes mediation between the organization and the citizen (Lipsky, 1980), boundary spanning refers to specific activities aimed at crossing organizational boundaries, sectors and/or domains (Needham et al, 2017; Williams, 2012). Street-level bureaucrats can certainly perform boundary spanning activities, but not all street-level bureaucrats are boundary spanners and vice versa. Boundary spanning activities can be performed by different employees at different levels in the organizational hierarchy, ranging from CEOs to front-line employees. Boundary spanning can be an emergent role as well as a dedicated function in which boundary spanning activities are explicitly part of the job description (Williams, 2012). Moreover, boundary spanners are not necessarily members of professional public, private or non-profit organizations. For instance, in the field of interactive governance, often certain representatives of community constituencies are identified as boundary spanners, crossing various organizational and institutional boundaries, making connections, building relationships, translating and transforming knowledge, and so on (for example Miller, 2008; Edelenbos et al, 2016). It should be pointed out that many of these individuals do in fact have experience of working in the public sector, and such experience is crucial in enabling them to act as boundary spanners in governance processes. This is an issue that we will explore further (see Chapters 5 and 6).

\subsection{RATIONALE AND AIMS OF THE BOOK}

The main objective of this book is to provide a more comprehensive understanding of, and insights into, boundary spanning behaviour (activities), antecedent, and outcomes. We aim (1) to provide a coherent overview (theory, relevance, description, and analysis) of the state of the art on boundary spanners and boundary spanning, and (2) to advance research on boundary spanning in the field of public management and governance.

Boundary spanning is a "rising concept" in different disciplines, including organizational science, business administration and management, and public management. It has its origins in organizational literature, but is increasingly applied in inter-organizational and (governance) network settings due to several societal developments. The increasing attention on (and need for) boundary spanning capacity is also reflected in the rise of publications using this concept. For example, a simple search in the database Scopus shows a rise in publications, especially in the past $10-15$ years, which make use of the concept: 13 publications used the term "boundary spanning" or "boundary spanner" in title/abstract/key words in 
2000, 48 publications in 2006, 89 publications in 2010, and 150 publications in 2016 (see Figure 1.1).

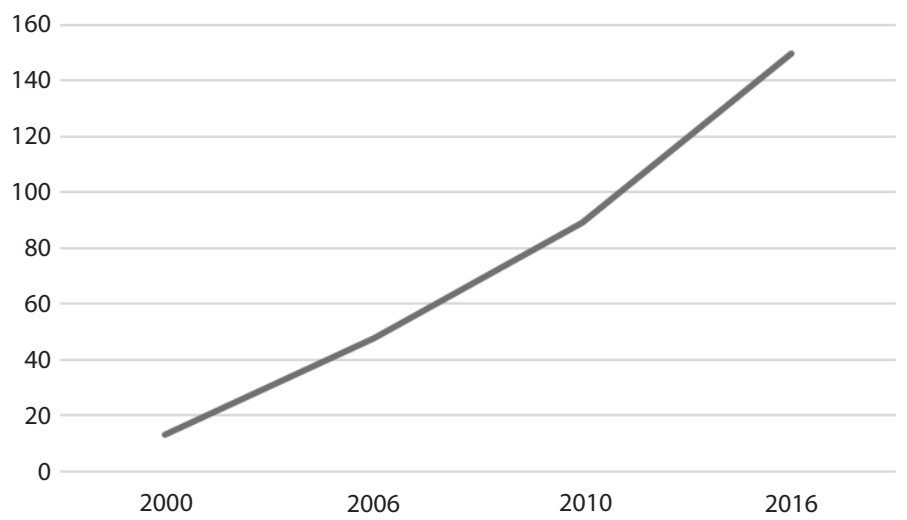

Source: Database Scopus

Figure 1.1 Publications with boundary spanning/spanners in title/abstract/key words in the period 2000-2016

Hence, there is quite some research on boundary spanning. However, this research is fragmented, hampering systematic accumulation of knowledge. Particularly in the field of public management and governance we lack systematic knowledge on core characteristics and activities of boundary spanners, antecedents of boundary spanning behaviour, and what the potential outcomes are of boundary spanning work. As Williams (2012: 146) observes: "The accumulated body of research on boundary spanners is not extensive, and in the absence of a greater depth and breadth of understanding boundary spanners in different contexts and challenges, with researchers sharing common understandings of the notion, achieving consensus will be difficult" (italics added). Also O'Flynn et al (2014), in their book on crossing boundaries in public management and policy, conclude that (p. 303):

An important area for future attention is bridging disciplinary differences. [...] Those looking to boundary crossing activity exclusively from the political science, organization studies, or public management perspectives will miss key parts of the puzzle. [...] There are important insights to be gained from across a range of disciplines, and scholars in particular may find that engaging with these different areas provides ways to move the field forward.

Therefore we aim to contribute to this accumulation of knowledge by bringing together various strands of literature, providing overview and to 
bring the research on boundary spanning in public management and governance further. To achieve these aims we include the knowledge of various disciplines on boundary spanning in this book, such as developed in business administration and management, organizational psychology, and public management and governance. In this respect we build on a systematic literature review of 249 articles on boundary spanners we conducted in 2016-2017. Box 1.2 provides a summary of this systematic review. Next to this extensive set of articles we build on several books treating the role and activities of boundary spanners or boundary spanning work (for example O'Flynn et al, 2014; Williams, 2012 - see also next paragraph). Furthermore, we build on our own quantitative and qualitative research on boundary spanners (for example Van Meerkerk and Edelenbos, 2014, 2016, 2017; Edelenbos et al, 2016).

This approach allows us to discuss boundary spanners from different theoretical viewpoints (Chapter 3). Moreover, it enables us to categorize different types of activities and roles that boundary spanners can employ (Chapters 4 and 5); to discuss different factors (antecedents) that influence the behaviour of boundary spanners (Chapter 6) and different impacts of boundary spanners (Chapter 7); and to provide an overview (Chapter 4) of the methods used (including potential methods) in examining boundary spanners and measuring their behaviour.

\section{BOX 1.2 SYSTEMATIC LITERATURE REVIEW OF ARTICLES ON BOUNDARY SPANNERS}

In order to get a comprehensive overview and broad range of studies on boundary spanners, we conducted a systematic review using the PRISMA approach (Moher et al, 2009). This means that we systematically searched and screened potential relevant publications. Key inclusion criteria we used:

- Empirical studies

- Studies should focus on boundary spanners crossing organizational or institutional boundaries (so excluding studies which only focus on intraorganizational boundary spanning)

- Studies should be published in English and in peer-reviewed journals

We searched the databases Scopus and Web of Science using the terms "boundary spanner" and "boundary spanning" (last search in March 2016). This resulted in nearly 2000 hits (1880). After screening the abstracts, applying the inclusion criteria, and excluding duplicates, the set was reduced to 588 articles. After full text screening, the final set came down to 249 articles.

Next we coded the articles on various themes: definition and measurement of boundary spanning, context of boundary spanning and background of boundary spanners (for example public, private, societal organization), theoretical approach, reported antecedents and effects of boundary spanning, and study design. 


\subsection{POSITION AND ADDED VALUE IN RELATION TO OTHER BOOKS ON BOUNDARY SPANNING}

Although boundary spanning and boundary spanners are long-existing concepts, which originates from organizational literature in the 1970s (see Chapter 3) and many articles have appeared since, surprisingly not many scholarly books have been published with an explicit focus on boundary spanners. This holds especially for public management and governance. To our knowledge, in this field there is only the eloquent book of Paul Williams (2012), Collaboration in Public Policy and Practice: Perspectives on Boundary Spanners. Williams approaches boundary spanners from a public management point of view, conceptualizing them as actors engaged in activities that cross traditional boundaries, such as organizations, sectors, professions, and policy. In his book he uses insights from his extensive research in Wales and he "adopts a predominantly UK focus" (p. 11). Williams' work is specifically focused on boundary spanners in collaborations among public organizations. He pays careful attention to different boundary spanning roles, and to the competences of and challenges facing boundary spanners. We build on his book and elaborate several aspects further, thereby also taking notice of his recommendations for future research. First, we pay explicit attention to further opening up the complex concept boundary spanner by dealing with specific characteristics, behaviours, activities, and roles (Chapters 3-5) as well as the measurement of boundary spanning (Chapter 4). Secondly, we pay systematic attention to the impacts of boundary spanning behaviour, for example in relation to trust-building, innovation, and (inter-)organizational performance (see Chapter 7). Thirdly, we go deeper into various antecedents of boundary spanning behaviour (Chapter 6). With the help of the systematic literature review we conducted, we included the insights of various disciplines that have contributed to theory building and testing of boundary spanning behaviour, factors and outcomes (although more work needs to be done in more systematically relating different types of antecedents, different types of boundary spanning behaviour and different types of outcomes).

Then there are several recent books in the public management and governance field dealing with boundary spanning strategies, while not explicitly focusing on the role of boundary spanners. For example, the edited volume of Bressers and Lulofs (2010) in the field of water governance, Governance and Complexity in Water Management: Creating Cooperation Through Boundary Spanning Strategies. This book focuses on complexity and unpredictability, two key challenges in 
contemporary water management. Although this book pays considerable attention to the concept of boundary judgments and discusses various boundary spanning strategies, it does not really deal with boundary spanning persons (their specific roles, profiles, antecedents, and outcomes). Moreover, it is exclusively focused on water management and in particular the Dutch water sector.

The edited volume of O'Flynn, Blackman and Halligan (2014) entitled Crossing Boundaries in Public Management and Policy deals more explicitly with boundary spanning in the public sector. The authors distinguish different types of working methods to cross boundaries, such as collaboration, networks, and whole-of-government, but do not have an explicit focus on the role of boundary spanners. In the same way, O'Flynn et al (2014) pay attention to enablers and barriers for working across boundaries, which is an inspiring point of departure for our book. It deals with discussing different types of boundaries (such as organizational, jurisdictional, or sectoral) and drivers for boundary crossing strategies and behaviour (see Chapter 2). However, these factors are discussed not in relation to boundary spanners, but rather in relation to boundary working in general (collaboration, joined-up government, etc.). While the authors view the boundary spanning person and leader who can stimulate boundary crossing work as an enabler, they do not elaborate on this observation.

In the field of business administration and management, there are several books on boundary spanning. One relevant book in relation to ours is Ernst and Chrobot-Mason's Boundary Spanning Leadership. Six Practices for Solving Problems, Driving Innovation, and Transforming Organizations (2011). The goal of the book is to develop case studies about boundary spanning leaders who have different backgrounds and identities. The book provides descriptive practices of boundary spanning leadership based on research conducted in the Center for Creative Leadership (CCL) in North Carolina, USA. In the book, boundary spanning is depicted as a leadership style; one that emphasizes "the ability to create direction, alignment, and commitment across boundaries in service of a higher vision or goal" (p. 5). Their argument is that by employing six specific leadership practices you create direction, alignment, and commitment between groups to achieve critical organizational outcomes. These practices are useful for learning more about boundary spanning leadership in a private sector context. In our book we take a more interdisciplinary approach. Furthermore, we do not limit our definition of boundary spanners to leadership positions in the organizational hierarchy: as argued above, boundary spanning activities can be performed by employees at different organizational levels. Furthermore, 
our aim is not to find universal practices, but to take the organizational and institutional context of boundary spanner into consideration. We do aim to find general key factors impacting on boundary spanning behaviour though (antecedents, see Chapter 6). Moreover, based on a wide range of empirical studies we review the impact of boundary spanning behaviour. This is also a different approach to Ernst and ChrobotMason's book.

In the field of marketing and sales, the recent edited volume of Sahadev, Purani and Malhotra (2015) deals with theoretical and empirical issues of salespeople depicted as boundary spanners. While Ernst and Chrobot-Mason (2011) focus on organizational leaders as boundary spanners, Shadev et al (2015) focus on front-line service employees as boundary spanners (i.e. salespeople). Building on this specific literature stream, they go deeper into various (organizational) factors in relation to role stress and their impact on goal orientation, behaviour, job satisfaction, and job outcomes among salespersons. They mainly take a role perspective on boundary spanners in this respect (see Chapter 3). We include various findings in this field of research in order to gain a better understanding of the various factors impacting on boundary spanning behaviour and of boundary spanners' job experience (job satisfaction, role stress) (see Chapter 6 on antecedents). However, Shadev et al's book for a large part deals with marketing specifics determining the boundary spanning role of salespersons. In our book we focus on the field of public management and governance, but also include the knowledge of different disciplines on boundary spanning.

\subsection{OUTLOOK ON THE BOOK CHAPTERS}

In this section we introduce the structure of the book and the content of each of the remaining seven chapters

Chapter 2 starts with an exploration of the developments in society, government and politics that increasingly lead to calls for boundary spanning behaviour in the field of public management and governance. Here, we deal with for example the increasing complexity of societal issues. However, this complexity is not confined to the public issues under consideration; it is also discernible in the institutional context in which these issues appear. Generating problem-solving capacity for these fiendishly difficult issues necessitates crossing organizational boundaries. Moreover, due to specialization and differentiation we see societies and organizations fragmentize and departmentalize, indicating the urge to cross boundaries and to restore coherence and wholeness. In addition, 
rising calls and demands for co-production and new forms of civic engagement, especially in the design and production of public goods and services, have emerged in the past decade. These initiatives also challenge traditional organizational and institutional boundaries vis-à-vis the design and delivery of public services. As discussed in Chapter 2, these developments push for cross-boundary work between the spheres of society, government and the business sector. Furthermore, we explore what the potential role of boundary spanners could be in relation to cross-boundary work as a consequence of these developments.

In Chapter 3 we discuss the theoretical evolution of boundary spanning and the different theoretical perspectives that exist. We start with its origin in organizational science and contingency approaches and develop and expand it to inter-organizational theories and governance network approaches. Boundary spanning theory started from an organizational perspective, which stressed the need for organizations to stay attuned to the wider environment (stakeholders) and (political, technological) context. It also evolved to an approach that focuses on collaborations, partnerships, and inter-organizational cooperation. In this chapter we distinguish and discuss three of the theoretical perspectives that have emerged: the structuralist perspective, the role perspective, and the action perspective. Each perspective approaches boundary spanners in a different way and highlights different aspects of boundary spanning behaviour. Furthermore, through building on the three perspectives discussed, we come to a definition of boundary spanners and elaborate on four key features.

Chapter 4 pays attention to detecting boundary spanners and measuring boundary spanning behaviour. We go deeper into various activities distinguished in the literature and specifically discuss methodological considerations in researching boundary spanners. This is especially relevant given the ambiguity surrounding the conceptualization of boundary spanners and the measurement of boundary spanning behaviour (for example Levina and Vaast, 2005). We provide an overview of empirical studies on boundary spanners and discuss the wide array of methods used in the study of boundary spanners. They vary from ethnographic research in developing profiles of boundary spanners to quantitative and mixed method designs. Whereas quantitative studies generally aim to measure certain types of boundary spanning activity, explain variations in boundary spanning behaviour, and test the effects of boundary spanning, qualitative studies aim to typify and contextualize boundary spanning activity. The overall purpose of this chapter is to critically reflect on and compare different methods and research designs used in the study of boundary spanners in order to enhance and facilitate future research. 
Moreover we thereby also aim to remove the ambiguity surrounding the conceptualization of boundary spanners and the measurement of their behaviour.

As boundary spanning is done by individuals with specific competences, relationships and experience, we aim to provide boundary spanners a face in Chapter 5. The theoretical aspects of boundary spanning discussed in Chapters 3 and 4 are useful in terms of helping us to understand the nature of boundary spanning activities and the role played by the boundary spanner; however, they do not tell us much about the personal motivations of boundary spanners, how they experience the work that they perform, and how they deal with the challenges they face in spanning different social, organizational, and institutional boundaries.

In Chapter 5 we are therefore going to profile boundary spanners in the context of public management and governance. We will contextualize boundary spanning, and discuss the qualities, competences and challenges of those individuals performing boundary spanning work. Moreover, as different contextual circumstances have a contingent relationship with boundary spanning roles, we elaborate four different boundary spanning profiles: the fixer, the bridger, the broker, and the innovative entrepreneur.

Boundary spanning does not take place in a vacuum; there are a lot of potential factors hampering or stimulating boundary spanning behaviour. However, in the field of public management and governance there is relatively little insight into the antecedents of boundary spanning behaviour. There is some research on individual competences (for example Weerts and Sandmann, 2008; Williams, 2002, 2012), but very little on organizational and environmental factors. As organizational psychology and business administration literature has picked up the topic of antecedents more extensively, we can learn a great deal from these studies. In Chapter 6, we distinguish and discuss different types of antecedents that influence boundary spanning behaviour. Based on our systematic literature review we distinguish the following types of antecedents: (1) individual determinants (such as capacities, experience, motivation, and commitment), (2) environmental characteristics (for example uncertainty, dependency, and dynamics), (3) organizational support and feedback (such as empowerment and management support), and (4) role definition and stressors (for example level of autonomy, role ambiguity, role conflict, and role overload). At the end of this chapter we will present and discuss a framework in which we relate these different antecedents and propose several avenues for future research. 
In Chapter 7 we discuss the impact of boundary spanners. A key question is whether the work of boundary spanners matters at all. What impact do boundary spanners have, for example on organizational and inter-organizational outcomes? Based on our systematic literature review, different kinds of impact can be distinguished, such as role stress and influence, organizational performance (for example innovation), relational quality (trust, collaboration), inter-organizational outcomes (network performance, synergy, and public value), and integration and alignment. These types of impacts will be extensively discussed. We will also highlight the absence of research on the relationship between types of behaviour or specific activities, on the one hand, and types of impact, on the other, before presenting and discussing a framework that goes deeper into these relationships.

Finally, we close the book in Chapter 8 by wrapping up the main insights as developed in the preceding chapters. We also develop a research framework for the further study of boundary spanners and boundary spanning in the field of public management and governance, taking into account emerging research themes and questions in order to facilitate future research. We also discuss some issues and guidelines for practitioners, especially for principals and line managers, who are in a position to create a fertile ground for boundary spanners on the job. Boundary spanning is a hard and challenging job that needs a productive context in order to become meaningful and effective in public management and governance settings. Furthermore, we pay attention to some key challenges that boundary spanners face in doing their job, for example balancing vertical and horizontal accountabilities; in supporting their home organizations; and in terms of managing their relationships with stakeholders in the network. An important part of the concluding chapter is devoted to constructing a dynamic and integral research framework in which we synthesize the various components of our book: the boundary spanning activities, the antecedents and context, the collaboration between boundary spanners, and the outcomes of boundary spanning work. This framework brings together insights from various studies of different disciplines and aims to enhance a more comprehensive perspective on boundary spanners. We thereby aim to stimulate and assist scholars and students in their study and future research efforts on boundary spanners. 


\subsection{A READERS' GUIDE}

We conclude this introductory chapter by providing a readers' guide (see Table 1.1), to help the reader to navigate their way through the book. Some chapters might be of more interest than others, depending on the specific demands and interests of the individual reader. If you cannot identify with any of the roles, you are of course free to find you own way through the book!

\section{Table 1.1 A readers' guide}

Who are you and what are you looking for?

I am a scholar / practitioner who wants to understand what the driving forces are behind the need for boundary spanning work.

I am a scholar who wants to know more about theories on boundary spanners / boundary spanning.

I am a scholar who wants to conduct an empirical study of boundary spanners and need advice on different methods of measurement.

I am a scholar in the field of public management and governance and want to find out more about the characteristics of a typical boundary spanner, and the work that they do.

I am a student who wants to get more acquainted with boundary spanning and boundary spanners.

I am a practitioner who would like to find out more about the work of boundary spanners.
Which chapter is particularly useful?

Chapter 2 deals with a number of drivers, for example increasing interdependency, emerging participative and self-organizing capacities of citizens, and the growing need to counter specialization and differentiation.

Chapter 3 on theoretical origins and perspectives is particularly useful.

Chapter 4 discusses how to identify boundary spanners and the range of methods that can be used to capture boundary spanning activities.

Chapter 5 on profiling boundary spanners offers four different profiles and provides illustrations from the field.

All chapters are relevant, but we suggest starting with Chapter 3, which provides a theoretical overview of boundary spanning from different scholarly disciplines.

Chapters 3 and 4 (on the different types of boundary spanning activities) and Chapter 5 (on different boundary spanning profiles) are the most relevant. 


\section{Table 1.1 (continued)}

\section{Who are you and what are you Which chapter is particularly useful? looking for?}

I am a scholar who wants to know more about factors influencing (helping or obstructing) boundary spanners' behaviour and their job experience.

I am a practitioner who needs advice on how my organization can facilitate boundary spanning employees.

I am a scholar/practitioner who wants to know what all the fuss is about what do boundary spanners really contribute?

I am a scholar/practitioner who wants to get a quick overview of what the book has delivered and what research proposals it contains.
Chapter 6 examines the different types of antecedents of boundary spanning behaviour, and provides an integral model that comprehensively captures influential factors.

Chapter 6 on antecedents discusses several important organizational factors. Chapter 8 provides an integral framework on relevant factors and relationships that can be taken into account in organizing and facilitating boundary spanners.

Chapter 7 on the impact of boundary spanners offers a review and discussion of the consequences of boundary spanning behaviour for organizations and inter-organizational relationships, and for boundary spanners themselves.

Chapter 8 summarizes the key insights of the book, discusses main themes and challenges, and provides a comprehensive (research) approach to (studying) boundary spanners. 